ДУБРОВИНА Ольга Васильевна - доктор политических наук, профессор, ректор Сибирского института международных отношений и регионоведения (630075, Россия, г. Новосибирск, ул. Народная, 14; dubrovinaov@list.ru)

ДУБИНИНА Оксана Юрьевна - кандидат политических наук, доцент Сибирского института международных отношений и регионоведения (630075, Россия, г. Новосибирск, ул. Народная, 14; dubinina2302@gmail.com)

\title{
ОСНОВНЫЕ НАПРАВЛЕНИЯ КУЛЬТУРНОЙ ДИПЛОМАТИИ СОВРЕМЕННОЙ ЯПОНИИ
}

Аннотация. Данная статья посвящена основным направлениям культурной дипломатии Японии. Авторы рассматривают продвижение японской культуры и языка, анализируют международное сотрудничество в области образования, исследуют помощь Японии развивающимся странам, изучают международные обмены и популяризацию японского языка в мире, а также выявляют институты, реализующие культурную дипломатию на государственном уровне.

Ключевые слова: Япония, Японский фонд, культурная дипломатия, международное сотрудничество, культурные обмены, популяризация японского языка

Постановка проблемы. В современном мире большинство стран придают особое значение политике в сфере культуры и все чаще используют термин «внешняя культурная политика». При успешной реализации эта политика способна стать эффективным средством сопровождения общей внешнеполитической стратегии государства, создавая прочный фундамент, позволяющий не только отстаивать и продвигать свои национальные интересы на мировой арене, но и оказывать непосредственное влияние на различные политические, экономические, социальные процессы в мире. Основным инструментом ее реализации выступает культурная дипломатия, или дипломатическая деятельность, связанная с использованием культуры в качестве объекта и средства достижения основополагающих целей внешней политики государства - создания благоприятного образа страны, популяризации культуры и языков ее народов, все чаще выступающая сегодня в форме общественной дипломатии [«Мягкая сила»... 2016: 94].

Культурная дипломатия - это использование государством существующих или специально установленных культурных, общественных и научных связей для достижения политических, дипломатических, пропагандистских целей. Культурная дипломатия существует на практике уже на протяжении столетий и на сегодняшний день является динамичной и инновационной областью научных исследований. Термин «культурная дипломатия» появился в 1930-х гг. и изначально имел явно выраженный пропагандистский оттенок [Василенко 2016: 67-68].

Культурная дипломатия использует культуру в качестве объекта и средства достижения основополагающих целей внешней политики государства с целью создания благоприятного образа страны, популяризации культуры и языков ее народов. Среди субъектов культурной дипломатии, как правило, называются органы государственного управления, хозяйствующие субъекты, привлекаемые государством как монополистом во внешнеполитической деятельности, неправительственные организации [Бафоев 2016].

Культурная дипломатия является важной составной частью государственной политики многих государств современного мира. Она охватывает культурногуманитарную сферу, ориентирована на интеграцию страны в мировое культурное пространство. Страны, обладающие необходимыми ресурсами, регулярно 
проводят музыкальные фестивали, кинопросмотры, выставки, организуют выступления творческих коллективов и известных деятелей искусства, некоторые страны организует работу школ, клубов, студий, объединений по интересам. Разумеется, в разных странах уровень причастности государства к международной культурной деятельности различен.

Актуальность темы исследования обусловлена важной ролью культурной дипломатии в качестве объекта и средства достижения основных целей внешней политики государства, формирования подходящего образа страны, популяризации ее культуры и языка. Проблема культурной дипломатии в настоящее время привлекает особое внимание ученых и политиков, что нашло отражение в публикациях И.А. Василенко, Э.В. Молодяковой, Е. Катасоновой, А.Е. Куланова, А.О. Наумова, Е.В. Василенко, В.А. Королева, С.С. Кудрявцевой. С целью исследования основных направлений культурной дипломатии современной Японии были рассмотрены основные понятия культурной дипломатии, проанализированы государственные институты, отвечающие за культурную дипломатию Японии, выделены и охарактеризованы пять направлений культурной дипломатии Японии. Были использованы такие общенаучные методы исследования, как анализ, синтез, дедукция, исторический и системный методы.

В современном мире большинство стран придают ей особое значение, и Япония относится к числу государств, которые активно, целенаправленно и успешно осуществляют свою культурную дипломатию во всем мире. Под культурной дипломатией в Японии понимается особый вид информационно-разъяснительной работы министерства иностранных дел. Она направлена на развитие понимания и доверия граждан иностранных государств по отношению к Японии, на установление благоприятной международной обстановки для проведения Японией своей внешнеполитической линии, а также на создание позитивного имиджа государства в мировом сообществе.

В соответствии с общепринятой современной практикой необходимость поддержания позитивного имиджа своей страны является обязательной для всех дипломатов. При этом в структурах министерств иностранных дел развитых стран нередко создаются специальные органы, отвечающие за культурную (или публичную) дипломатию. В составе МИДа Японии такая задача возложена на входящий в секретариат министра департамент публичной дипломатии и на подчиняющиеся ему информационные центры (отделы) посольств Японии за рубежом [Куланов 2007: 116].

Культурная дипломатия использует элементы культуры с целью создания позитивного отношения иностранцев к населению страны, расширения сотрудничества между странами, изменения политической среды страны, защиты национальных интересов, предотвращения и смягчения последствий конфликтов между странами. Культурная дипломатия может использовать все аспекты национальной культуры, такие как искусство, включая кино, музыку, живопись и т.д.; выставки, на которых демонстрируются многочисленные объекты культуры; образовательные программы, направленные на изучение языков за рубежом; обмен научными, образовательными и иными достижениями; литература (перевод популярных произведений); трансляция новостных и культурных программ; религия, включая межрелигиозный диалог; пропаганда идей социальной политики.

Культурная дипломатия, когда она изучается и применяется на всех уровнях, обладает уникальной способностью влиять на глобальное общественное мнение и идеологию отдельных лиц, общин, культур или наций.

Министерство иностранных дел Японии отмечает важность культурной 
дипломатии во внешней политике государства. Культурная дипломатия, в отличие от традиционной дипломатии, работает непосредственно с иностранными гражданами и общественным мнением посредством культурного обмена и связей с общественностью. Среди основных направлений культурной дипломатии Японии можно выделить такие, как продвижение японской культуры и языка, международное сотрудничество в области образования, помощь развивающимся странам, международные обмены, популяризация японского языка.

Первым направлением занимается в первую очередь Японский фонд (The Japan Foundation). Он был учрежден в 1972 г. как особое юридическое лицо под эгидой Министерства иностранных дел Японии, а в 2003 г. получил статус независимой административной организации. Сегодня фонд располагает 24 зарубежными отделениями в 23 странах мира. Японский фонд ведет деятельность по трем основным направлениям: программы обмена в области культуры, программы по преподаванию японского языка за рубежом, программы поддержки исследований по Японии и интеллектуальных обменов ${ }^{1}$. В целом, Японский фонд является стержнем культурного обмена, который осуществляет Япония со странами мирового сообщества.

Помимо Японского фонда, к институтам, реализующим культурную дипломатию Японии, можно отнести Агентство по культуре, действующее в рамках Министерства образования, культуры, спорта, науки и техники и МИДа Японии, а также японские центры, созданные в конце XX в. в развивающихся государствах [Мошняга 2009: 159]. Японские центры предоставляют информацию о Японии зарубежной общественности. Их основная цель заключается в привлечении внимания к вкладу Японии в содействие развитию, а также в подготовке кадров для бизнеса в принимающих странах и создание благоприятной почвы для развития сотрудничества между местным и японским бизнесом. Сегодня такие центры расположены в 9 странах, в т.ч. в 4 бывших республиках СССР. Они реализуют три вида программ: бизнес-курсы, курсы по изучению японского языка и программы, направленные на улучшение взаимопонимания и двусторонних отношений между Японией и государством, где расположены эти центры. По сути, японские центры, наряду с Японским фондом, являются основным инструментом культурной дипломатии Японии [Наумов 2016: 191].

В Японии первоначально традиционный подход к распространению японской культуры в мире базировался главным образом на экспорте традиционных культурных ценностей, таких как театр кабуки, чайная церемония или икебана. Их продвижение во внешний мир было призвано показать историческую значимость Японии и ее многовековой культуры для мирового наследия.

Однако в настоящее время именно современный культурный слой открывает кратчайший путь к завоеванию популярности Японии в мире, возникновению массового интереса к глубинам японской истории и культуры. Важным инструментом реализации потенциала культурной дипломатии является проект Cool Japan, пропагандирующий субкультуру японской молодежи (поп-музыка, косплей, аниме, манга). В переводе на русский язык cool означает особенный, крутой, классный - термины, наиболее понятные в молодежной среде. Проект Cool Japan направлен прежде всего на молодежь зарубежных стран - наиболее динамичную и наименее консервативную часть любого общества посредством

1 Японский фонд. Официальный сайт. Доступ: http://jpfmw.ru/ru/about/o-fonde.html (проверено 26.12.2018). 
различных мероприятий, демонстрирующих необычные для других стран элементы японской культуры и традиций [Чугров 2015: 62-63].

Япония может выступать в качестве государства с подлинно азиатскими ценностями и как западное государство, адаптирующее массовую культуру Запада, начиная с Америки, для своего населения и населения стран региона. Использование того или иного образа помогает Японии обеспечить адекватное восприятие страны различными национальными и региональными аудиториями [Катасонова 2009: 57].

Под индустрией культуры подразумевается продукция легкой промышленности, дизайн и мода, продукция пищевой промышленности, национальная кухня, производство посуды и кухонной утвари, элементы теле-, кино- и видеоиндустрии, медиаконтент, туризм, ремесленное производство, в т.ч. широкий ассортимент товаров народных промыслов. К 2020 г. Япония планирует завоевать 9-11\% этого сегмента мирового рынка. Среди стран, в которых Япония в ближайшие годы намерена наращивать влияние своей индустрии культуры, лидируют Индия и Китай, в которых объем этого сегмента рынка, согласно прогнозам, вырастет к 2020 г. на 11\%. Второе место по прогнозируемым темпам роста делят Россия, Бразилия и Индонезия (по 10\% каждая). На третьем месте - Саудовская Аравия и Таиланд (по 8\%). Далее следует Сингапур - 7\%. Темпы роста этого рынка в Италии составят 5\%, в США, Франции, Турции, Южной Корее и Гонконге - по 4\%, в Германии, Испании и Южной Африке - по 3\% [Королев, Кудрявцева 2014: 196].

На втором направлении - в международном сотрудничестве в области образования - Япония играет все возрастающую роль на международном рынке. Токио активно привлекает на обучение иностранных студентов. Сотрудничество в области образования играет все возрастающую роль на мировом рынке образовательных услуг. В июле 2008 г. Япония разработала план «300 000 International Students» с целью приема к 2020 г. 300 тыс. иностранных студентов. Реализуются различные стипендиальные программы, позволяющие иностранным студентам получать дипломы и сертификаты в ведущих университетах Японии. Активно продвигается и межуниверситетское сотрудничество японских и зарубежных вузов, подразумевающее установление партнерских отношений между ними, разработку и реализацию совместных международных образовательных программ.

В 2009 г. Министерство образования, культуры, спорта, науки и технологии (МПКСНТ) Японии для реализации этой цели запустило проект «ГЛОБАЛ 30», направленный на стратегическое международное сотрудничество и формирование центров интернационализации образования в Японии. Для реализации проекта были отобраны 13 университетов Японии, которые получают финансовую помощь в размере 200-400 млн иен в год в течение 5 лет. Согласно этому плану, для создания эффективной образовательной и исследовательской среды для иностранных студентов университеты будут обязаны: 1) организовать проведение курсов, по окончании которых выпускники могут получить соответствующие степени; 2) усовершенствовать систему приема иностранных студентов, организацию стажировок в японских корпорациях; 3) предоставить иностранным студентам возможность изучать японский язык и культуру Японии; 4) содействовать стратегическому международному сотрудничеству (создание за рубежом двух отдельных представительств от каждого университета, возможность проводить отбор местных кандидатов посредством вступительных тестов и т.д., увеличение числа японских студентов, обучающихся за границей по программам обмена и др.). В итоге иностранные студенты, принявшие участие в японских университетских 
программах, становятся проводниками интересов Японии в своих странах [Королев, Кудрявцева 2014: 197-198].

Третье направление культурной дипломатии Японии включает в себя официальную помощь развитию (ОПР). Данную деятельность Япония начала осуществлять в 1954 г., когда официальный Токио присоединился к международной организации «План Коломбо», цель которой заключается в поддержании экономического и социального развития стран Южной и Юго-Восточной Азии, а также Тихоокеанского региона. С этого момента Япония стала реализовывать программы технической и финансовой помощи развивающимся странам. Японская система официальной помощи развитию подразумевает в первую очередь выделение грантов и кредитов. Ответственность за данный вид деятельности возложена на Японское агентство международного сотрудничества. Сегодня эта структура работает более чем в 150 государствах и имеет около 100 представительств за рубежом [Королев, Кудрявцева 2014: 200]. На протяжении многих лет Япония является основным донором для ряда стран Азии и Африки, в частности для Вьетнама, Монголии, Лаоса, Камбоджи. В последнее время «мягкая сила» Японии в данном формате продвигается и на постсоветском пространстве. А в Латинской Америке, например, японская «мягкая сила» наиболее активно реализуется в Бразилии [Наумов 2016: 192].

Гранты как инструмент «мягкой силы» подразумевают выделение финансовых средств на конкретные проекты развивающимся странам с низким уровнем дохода без необходимости их возврата. Средства направляются на повышение качества функционирования основных инфраструктур - школ, больниц, средств водоснабжения, дорог, а также налаживание систем здравоохранения и медицинского обслуживания, приобретение оборудования и др. Другая форма помощи за счет грантов включает в себя техническое сотрудничество с целью развития людских ресурсов и формирования административных систем в развивающихся странах и предполагает отправку специалистов, предоставление необходимого оборудования и подготовку персонала из развивающихся стран в Японии и других странах. Правительственные займы предоставляются Японией в соответствии с международной практикой при условии, что развивающаяся страна погасит их в будущем [Королев, Кудрявцева 2014: 200].

Япония оказывает культурную поддержку развивающимся странам. В целях содействия развитию культуры и высшего образования в этих странах и углубления взаимопонимания и дружбы с Японией Министерство иностранных дел предоставляет безвозмездную помощь в области культуры в рамках официальной помощи развитию. В рамках сотрудничества по линии общих культурных грантов государственным учреждениям развивающихся стран выделяются необходимые средства на приобретение звукового и светового оборудования для объектов культуры, учебного оборудования для высших учебных заведений, улучшение культурного наследия и музеев, а также на приобретение спортивного инвентаря для различных видов спорта, включая дзюдо и японские боевые искусства. Также ведется большая работа по защите материального и нематериального культурного наследия через ЮНЕСКО (Организация ООН по вопросам образования, науки и культуры).

$\mathrm{K}$ тому же японское правительство уделяло и уделяет чрезвычайно серьезное внимание политике по сохранению и увековечению национальных культурных ценностей на территории всей страны, а также проводит масштабную работу по пропаганде своей культуры в целом в рамках культурной дипломатии. В этих рамках Япония чрезвычайно плодотворно сотрудничает с ЮНЕСКО. Из 195 стран - членов ЮНЕСКО Япония принимает непосредственное участие в управлении организацией как член Исполнительного комитета, поддержи- 
вает финансирование ЮНЕСКО в качестве второй по величине страны-донора после Соединенных Штатов Америки и принимает решение о содержании проектов ЮНЕСКО ${ }^{1}$.

Признавая важность сохранения ценнейшего культурного наследия, японское правительство активно взаимодействует с разными странами, поддерживая их усилия по сохранению национальных сокровищ. С этой целью был создан Японский трастовый фонд сохранения всемирного культурного наследия и аналогичный фонд сохранения и поощрения нематериального культурного наследия. Озаботившись проблемой сохранения всемирного культурного наследия, в 1972 г. на своей XVII сессии ЮНЕСКО приняла Международную конвенцию об охране культурного наследия. Япония присоединилась к этой конвенции лишь спустя 20 лет, в 1992 г., став 125-й страной, подписавшей этот документ. В соответствии с Международной конвенцией Комитет по всемирному наследию, состоящий из представителей 21 государства, принимает различные решения по вопросам всемирного наследия. Япония активно участвует в его работе. Начиная с 1993 г., т.е. сразу же после присоединения к Конвенции, Япония в течение 6 лет была его членом. За неполные 15 лет Япония сделала очень много для реализации задач, поставленных Конвенцией, и в целом активно участвовала в деятельности ЮНЕСКО. Усилия страны по достоинству были оценены избранием в октябре 2005 г. на пост генерального директора этой организации дипломата Мацуура Коитиро, бывшего до этого назначения послом во Франции. В 1999 г. в г. Нара, который фактически является музеем под открытым небом, был учрежден Азиатско-тихоокеанский культурный центр при отделе сотрудничества по защите культурного наследия ЮНЕСКО. Это можно также рассматривать как признание немалых заслуг Японии по сохранению культурных ценностей как внутри страны, так и в мировом масштабе [Япония... 2007: 37].

Кроме того, ЮНЕСКО является одной из немногих международных организаций, в которой численность японского персонала достигла желаемого уровня в плане географического распределения. 49 японских сотрудников были направлены в штаб-квартиру ЮНЕСКО в Париже и в региональные отделения по всему миру. В Японии насчитывается 21 объект, входящий во всемирное наследие: 17 культурных памятников и 4 природных. В 2017 г. в список всемирного наследия были внесены остров Окиносима в Мунаката и связанные с ним места поклонения ${ }^{2}$.

В качестве стратегического партнера ЮНЕСКО Япония, особенно уязвимая в области стихийных бедствий, также сотрудничает с Организацией по вопросам предотвращения опасности стихийных бедствий и смягчения их последствий. Благодаря поддержке Японии был начат крупный проект по ликвидации неграмотности среди женщин в Афганистане; пользу от проекта получили 750 тыс. чел. Япония - один из ключевых партнеров ЮНЕСКО в деле обсуждения и определения принципов, которыми должна руководствоваться разработка искусственного интеллекта. Япония совместно с ЮНЕСКО организовала круглый стол на тему: «Искусственный интеллект: осмысление его комплексного характера и влияния на наше общество», который состоялся в ЮНЕСКО 11 сентября 2018 г. ${ }^{3}$

\footnotetext{
${ }^{1}$ Министерство иностранных дел Японии. Официальный сайт. Доступ: https://www.mofa.go.jp/mofaj/ comment/faq/culture/gaiko.html\#section6 (проверено 26.12.2018).

2 Объекты Всемирного наследия ЮНЕСКО в Японии. Доступ: https://www.nippon.com/ru/features/ h00166/ (проверено 26.12. 2018).

3 Новая глава стратегического партнерства между Японией и ЮНЕСКО. Доступ: https://ru.unesco. org/news/novaya-glava-strategicheskogo-partnerstva-mezhdu-yaponiеу-і-уunesko (проверено 26.12. 2018).
} 
Направлением культурной дипломатии Японии являются также международные культурные обмены, принесшие ей успех еще в середине XX в. Это взаимные визиты представителей общественности и программы образовательных и спортивных обменов; обмены в области культуры и искусства между ведущими научными специалистами и деятелями науки и культуры, диалоги между цивилизациями, развитие японоведения. Программы образовательных, молодежных и спортивных обменов считаются одними из наиболее перспективных, т.к. направлены на создание положительного образа Японии среди тех, кто в будущем, возможно, составит политическую, экономическую, интеллектуальную элиту своих стран. Успешно работает Программа обмена и преподавания в Японии (Japan Exchange and Teaching - JET), предназначенная для желающих преподавать английский в школах и университетах (по этой программе Японию на срок от 1 года до 3 лет посетили более 40 тыс. молодых иностранцев из более чем 40 стран мира). МИД Японии поощряет развитие спортивного обмена, в т.ч. пропаганду за рубежом традиционных японских единоборств, прежде всего дзюдо и кэндо.

Распространены также обмены в области культуры и искусства - проведение фестивалей японского кино, а также многочисленные выставки и концерты. С особым вниманием правительство Японии относится в последнее время к продвижению молодежной субкультуры, считая ее перспективным компонентом, подготавливающим молодежь других стран к восприятию и пониманию традиционной культуры Японии.

Большое внимание уделяется интеллектуальным обменам, развитию японоведения. Одновременно японская наука, занявшая во многих областях человеческих знаний передовые позиции в мире, активно ищет возможности сотрудничества с учеными других стран для расширения научных контактов и оптимизации научного процесса в самой Японии. Япония также проводит мероприятия по привлечению иностранных специалистов в области средств массовой информации (журналистов, аналитиков, телеведущих) для стажировки в Японии. Лучшие математики, физики, химики, ихтиологи и другие ученые из самых разных стран мира, в т.ч. из России, активно привлекаются к процессу интеграции как в Японии, так и за ее пределами путем организации различных конференций, симпозиумов, семинаров и стажировок [Куланов 2007: 129].

По-прежнему широко используются информационные поводы, позволяющие проводить целевые акции, направленные на продвижение положительного образа Японии, часто приуроченные к тем или иным памятным датам. Япония регулярно участвует в ставших уже доброй традицией перекрестных Годах культуры между странами. Основная цель организации перекрестного года - дальнейшее развитие и укрепление двусторонних отношений. Множество мероприятий, проходящих в рамках Года, позволяют увидеть и оценить культурные достижения других стран. Музыканты, художники, артисты, режиссеры и многие другие представители творческих профессий приезжают в другую страну, чтобы поделиться культурными и историческими ценностями своей родины и внести вклад в общее дело укрепления дружбы и взаимопонимания на международной арене. В частности, 2018 г. прошел как Год России в Японии и Год Японии в России (о его проведении министерства культуры двух стран договорились в декабре 2016 г. во время визита президента РФ В.В. Путина в Японию) ${ }^{1}$.

Кроме того, существуют мемориальные проекты, среди которых можно назвать такие, как «150-летие установления дипломатических отношений

\footnotetext{
1 Официальный сайт Администрации Приморского края. Доступ: https://www.primorsky.ru/news/130028/ (проверено 26.12. 2018).
} 
между Данией и Японией», «50-летие установления дипломатических отношений между Японией и Мальдивами» (2017 г.), «40-летие со дня установления дружественных отношений и сотрудничества между Японией и ACEAН» (2013 г.), «60-летие со дня вступления Японии в Организацию Объединенных наций» (2016 г.).

Популяризацию японского языка в мире эффективно осуществляет МИД Японии. Японское языковое образование в зарубежных странах очень важно, т.к. оно способствует развитию обмена с Японией, углублению понимания Японии и созданию основы дружественных отношений с зарубежными странами. В 137 странах и регионах мира около 36600000 чел. изучают японский язык (обзор Международного валютного фонда в 2015 г. ${ }^{1}$ ).

Министерство иностранных дел Японии через информационные отделы своих посольств, где собирается значительная часть интересующей министерство социологической информации и через которые идет официальное знакомство с этой страной, а также через специальные японские центры продолжает популяризировать японский язык во всем мире. В информационных отделах и японских центрах, как правило, накапливаются значительные объемы информации в виде книг, аудио- и видеоматериалов по самым разным областям жизни, истории, культуры, традиции и политики Японии, которые передаются во временное пользование местным средствам массовой информации на безвозмездной основе. С недавнего времени особые возможности на этом направлении открылись благодаря повсеместному распространению сети Интернет. Интернет дает возможность почти неограниченного доступа к материалам по культуре, традициям и социально-экономическим успехам Японии [Куланов 2007: 126].

Культурная дипломатия Японии является сегодня одним из наиболее приоритетных направлений внешнеполитической деятельности этой страны. В стремлении достичь цели Япония действует путем пропаганды своих ценностей, создания позитивного имиджа пацифистского государства, финансовой поддержки, методами просвещения и убеждения, а не насильственной пропаганды. При этом культурная дипломатия позволяет Японии эффективно решать самые разные задачи политического и экономического характера и способствует более глубокой интеграции страны в международное сообщество. Опыт Японии и ее высокая квалификация в сфере культурной дипломатии актуален для России и способен стать ориентиром для других стран с собственным значительным культурным потенциалом.

\section{Список литературы}

Бафоев Ф.М. 2016. Культурная дипломатия в системе международных связей на постсоветском пространстве. - Молодой ученый. №6. С. 662-667.

Василенко Е.В. 2016. Культурная дипломатия как инструмент «мягкой силы» государства. - Перспективы: электронный журнал. № 1(5). С. 66-79.

Катасонова Е.Л. 2009. Япония: поп-дипломатия и поп-культура. - Мировая экономика и международные отношения. № 2. С. 56-63.

Королев В.А., Кудрявцева С.С. 2014. «Мягкая сила» современной Японии: опыт и направления развития. - Вестник междуународных организаций. Т. 9. № 2. С. 190-208.

Куланов А.Е. 2007. Культурная дипломатия Японии. - Япония: ежегодник. Вып. 36. С. 116-130.

\footnotetext{
1 Министерство иностранных дел Японии. Официальный сайт. Доступ: https://www.mofa.go.jp/mofaj/ comment/faq/culture/gaiko.html\#section6 (проверено 26.12.2018).
} 
Мошняга П.А. 2009. Внешняя культурная политика Японии. - Власть. № 6. C. $159-161$.

«Мягкая сила» в азиатско-тихоокеанском региональном контексте.

Теоретическая адаптация и национальные практики: монография (под ред. С.К. Песцова). 2016. Владивосток: Изд-во ДФУ. 192 с.

Наумов А.О. 2016. «Мягкая сила» Страны восходящего солнца. Международные отношения. № 2. С. 189-193.

Чугров С.В. 2015. Мягкое притяжение Японии. - Полис. Политические исследования. № 6. С. 53-67.

Япония, открытая миру (под ред. Н.П. Дмитриевской). 2007. М.: АИРО-ХХІ. $308 \mathrm{c}$.

DUBROVINA Ol'ga Vasil'evna, Dr.Sci. (Pol.Sci.), Professor; Rector of the Siberian Institute of International Relations and Regional Studies (14 Narodnaya St, Novosibirsk, Russia, 630075; dubrovinaov@list.ru)

DUBININA Oksana Yur'evna, Cand.Sci. (Pol.Sci.), Associate Professor of the Siberian Institute of International Relations and Regional Studies (14 Narodnaya St, Novosibirsk, Russia, 630075; dubinina2302@gmail.com)

\section{MAIN DIRECTIONS OF CULTURAL DIPLOMACY OF MODERN JAPAN}

Abstract. This article analyzes cultural diplomacy as the top-priority direction of Japan's foreign policy. The authors distinguish such main directions of cultural diplomacy as promotion of Japanese culture and language; international cooperation in education; assistance to developing countries; international exchanges; popularization of the Japanese language. The promotion of Japanese culture in the countries of the world community is based on the export of traditional cultural values (Kabuki theatre, tea ceremony, ikebana art). Now the authorities of Japan actively implement the project "Cool Japan", designed primarily at the youth audience. The Japanese government pays serious attention to the policy of preservation of national cultural values in the territory of the whole country, and for this purpose, it very fruitfully cooperates with UNESCO. Cultural diplomacy allows Japan to address effectively various political and economic problems and contributes to the country's deeper integration into the international community. The experience of Japan and its high qualification in the sphere of cultural diplomacy is relevant for Russia and other countries with their own significant cultural potential.

Keywords: Japan, cultural diplomacy, international cooperation, cultural exchanges, promotion of Japanese language, Japanese Foundation 